\title{
Teaching the Simple Strategy as an Inclusive, Student Support Intervention in a Tertiary Setting
}

\author{
Zuwena N.N. Williams-Paul \\ The University of the West Indies
}

Higher Education Institutions within the Caribbean continue to be reactive concerning student support services and interventions. This work highlights the importance of teaching Internal Control (Internality) to Externals detected on entry, as a proactive, inclusive, student support service intervention. The study employed a quantitative methodology and a survey, quasi-experimental research design. One sample of Externals flagged on entry as possibly high-needs/risk, was taught the 'SIMPLE' strategy (Internality instruction). Both the Control and Treatment groups of Externals were re-tested at Time 2, and similar to previous research, the mean Locus of Control (LoC) scores of the treatment group had desirably reduced.

\section{INTRODUCTION}

This research advances the case that an institution's obligatory efforts to removing barriers in an effort to maximize the student experience must, commence on entry as a proactive student support service and intervention measure, and be sustained during students' sojourn. It thus advocates for blended admissions screening, for the proactive detection (Early Alert Program trigger) of students having an External Locus of Control Orientation and other maladjusted attributions on entry to university. It also advocates for the teaching of Internal Control (Internality training) to these External students so that in addition to the regular suite of student support services available, this can also be an addition that will serve to change the student support landscape and thereby have far-reaching and positive strategic implications that will benefit the institution and all stakeholders in the face of increasing diversity among student cohorts.

A great majority of past research conducted with the Locus of Control construct was exploratory in nature and served to investigate cause and effect relationships, its mediating effect between independent and dependent variables or to explore the characteristics and profiles of Internals and Externals in various international contexts. This research is unique in that, apart from identifying students who were considered as at-risk for underachievement and other adverse and maladjusted attributions, it went further to investigate the effectiveness of teaching Internal control to a Caribbean sample which before, has never been attempted.

Such an intervention was only ever successfully attempted in an elementary setting in the Philadelphia area in 1972 by Hill and his colleagues (Hill, 2011b). In this current research however, the researcher who is a certified trainer, altered the tenets of the six-step Personal Achievement Strategy (PAS) treatment developed by Hill and his colleagues in an effort to ensure that the content was 
appropriate for college-age students in the tertiary setting, and this is the treatment which was used in this research and was termed the SIMPLE Strategy.

Of 108 new undergraduate External students (having scored within the range of 16-40 on the Norwicki \& Duke, LoC scale) detected on entry to a Caribbean university, 55 indicated their interest to progress to the advanced stages of the research which involved forming part of a Control $\left(\mathrm{C} ; \mathrm{n}_{1 \& 2}=25\right)$ and Treatment $\left(\mathrm{T} ; \mathrm{n}_{1}=30 ; \mathrm{n}_{2}=24\right)$ Group. The Treatment Group received the SIMPLE Strategy 'Internality' Instruction (appendix A) and both the Treatment and Control Groups were retested $\left(\mathrm{C}: \mathrm{n}_{2}=25\right.$ and $\mathrm{T}$ : $\left.\mathrm{n}_{2}=24\right)$ at the end of the first semester to determine whether their scores had moved closer to the score range of 0-6 which is representative of Internality (' $i L \boldsymbol{C o C}$ '-Internal LoC Orientation) and considered to be a more desirable orientation for academic success and overall wellbeing.

\section{Inclusiveness in Student Services design and delivery in the tertiary setting}

According to UNESCO (2005, p.16) inclusion is a moral imperative which "...focuses on the careful monitoring of those groups of learners who may be statistically most at risk for underachievement, marginalization and exclusion, so that all is done to ensure that they access, participate and achieve within the education system".

In keeping with such an imperative, one way for Higher Education Institutions (HEIs) to practice inclusion is to also conduct psychological risk assessments (non-cognitive screening) for new students i.e. proactively identify on entry, students who have maladjusted attributions and other at-risk orientations so that such students can be on track to receive on entry, targeted, needs-specific student support services throughout their stay at the institution.

Florian, Rouse and Black-Hawkins, (2016) stated that:

"the relationship between inclusion and achievement is complex ....A fundamental structural problem of equal opportunity lies at the heart of a system where those considered capable of high achievements are encouraged to stay at school and beyond into higher education, while those who struggle, because their learning needs are not properly addressed or their parents are not able to advocate for their interests, may be marginalised in school or leave education at the earliest opportunity. Thus, in many cases, the more successful the student, the greater the educational opportunities to learn he or she is given; the less successful the student, the fewer he or she is allowed. The consequent 'achievement gap' between the lowest and highest achievers has been of great concern in recent years, ..... hence, current policy initiatives focusing on 'closing the gap' between the highest and lowest achievers. Unfortunately, most previous efforts to do so have not been very successful (Perry \& Francis, 2010)".

This research advances one way to close the gap alluded to by Florian, Rouse and Black Hawkins. It proposes the optimisation of collaborative efforts of the Student services and admissions arm of universities toward this mission. It entails employing the Locus of Control construct as a means to flag vulnerable students. This is where the blended admissions (cognitive and non-cognitive screening) principle and process will, through enaction, set the stage for an Early Alert Program (EAP) that is proactive and strategic in its design and approach.

According to Golding, Gregory, Iles-Caven and Nowicki (2017), "Locus of Control (LoC) measures expectancies regarding one's ability to affect what happens in one's life and how what happens is based on their actions/behaviour". They went on to explain that "the more one believes that one's behaviour affects what happens, the more internal one is and a person is more external if he/she believes that what happens to him/her is a function of, or determined by luck fate, chance or powerful others".

Most significantly, is that numerous research confirm that Externality ('eLoC'- Having an external LoC Orientation), is characteristic of adverse outcomes and maladjusted attributions and perceptions since the perception of Externals is that there is little to no connection between their actions and consequences or life outcomes. (Halpert \& Hill, 2011; Hill, 2011a, Hill, 2011b, Rotter, 1966 and 1990). 
Such an orientation is thus troubling and should be proactively detected on entry as the first step in a series of inclusive intervention initiatives, to be meted out to students, as a means to reduce 'atriskedness' for underachievement and other challenges.

As Externals attribute their success and failures to external forces (fate, chance, or powerful others), and so, do not exhibit personal control, they are considered to have maladjusted attributions and may be at risk for underachievement, reduced well-being and other undesirable behaviors, thought processes, challenges and ascriptions. They also seek to avoid responsibility and surrender to the limitations of their situation believing, that such situations do not permit them to have a real chance in life or toward achieving personal results. Such perceptions according to Hill (2011b), can affect their goal setting and achievement behavior/outcomes.

On-entry identification and flagging of Externality is thus a proactive and much needed measure particularly, in the tertiary setting where inter alia, higher order, critical thinking and personal effort are necessary for success. As such, 'incubation' efforts that support diversity, inclusiveness and retention whereby, students during their stay at the institution are supported and sustained at the most favorable and optimal conditions for their growth and development, are indeed paramount, and can serve as an essential student support service intervention to reduce at-riskedness and many other challenges. Detecting such on entry via an 'Early Alert' mechanism is the first step and a proactive measure to meeting students at the point of their need(s).

\section{Statement of the Problem}

In 1971, Rotter indicated, that "College students feel more powerless to change the world and control their own destinies" p.59)..... "had become increasingly external in their locus of control during the late 1960 s and early 1970 s"...... and "that active steps should be taken to reverse this troubling trend".

Over thirty years later, Twenge, Zhang, and Im (2004), confirmed that "college students and young people's locus of control scores had substantially become even more external (about 0.80 standard deviations) between 1960 and 2002". They also concluded their publication by stating that, "in many ways, the continued increase in externality has made Rotter's prediction come true; many members of modern society feel alienated and apathetic" (p. 317)

These research were conducted in international settings and contrastingly, this current research was conducted in a Caribbean setting in 2016 which is twelve years after Twenge, Zhang, and Im's study and over thirty years since Rotter's study in 1971. In the Caribbean context, cultural and demographic profiles vary, the social capital is quite different and yet, similar to these previous research, Externality was high. It is thus not surprising that many studies on Locus of Control posited that internal LoC (iLoC; Internality) is a more desirable orientation (Hill, 2011a, 2011b; Halpert \& Hill, 2011; Olani, 2009; Pannells, 2008; Skinner, 1996). Additionally, as increased access is a strategic mandate for the university under study, and surmounting evidence continues to support the increasing diversity of student cohorts both nationally and internationally, more needs to be done by HEIs to close the gap between high and low achievers so that inclusion does not stop at widened access and inclusive technologies within the classroom setting, but that inclusive efforts are extensive, proactive and all-encompassing thereby, increasing the inclusion and potential of at-risk, vulnerable and high needs groups such as Externals.

\section{Research Objectives}

The aim of this research was to:

1. Teach Internality to a sample of new undergraduate students who scored as Externals (scores 16-40) on entry to the university under study

2. Re-Test these students at the end of the semester to determine whether their scores had reduced and moved toward the Internality score range of 0-6 which is most desirable

3. Advance recommendations for teaching the SIMPLE strategy as a proactive, inclusive student support service intervention initiative in the tertiary setting 


\section{LITERATURE REVIEW}

Notwithstanding the intellectual capacity of any individual, strive, grit, persistent effort and perceived control will guarantee the edge above all the rest particularly, in an academic setting. Jowkar, Kojuri Kohoulat and Hayat (2014) spoke to this fact in their study which examined the relationship between achievement goal orientation and academic resilience when they concluded that "achievement goal orientation has a critical role in students' academic achievement".

Lefcourt (2014) indicated that a proclivity to engage in academic tasks, expend effort and persist, promotes achievement and is characteristic of students who are of the belief that they have control over their success and failures. Such traits are indicative of Internality as Internals exhibit traits of goal achievement, determination, motivation and the like which research confirms are determinants of success and retention (Kader, 2014; Hadsel, 20110; Landrum, 2010; Halpert \& Hill 2011; Hill, 2011a \& 2011b).

In a study to investigate the effectiveness of goal setting skills in the English Language academic performance of senior secondary students, goal-setting skills had a significant influence on students' performance (Abe, Ilogu, \& Madueke, 2014). It was also recommended in this study that, "by setting and eagerly pursuing SMART goals, students demonstrate as they should, that they have adopted a positive attitude to their studies irrespective of gender, family history or circumstance" (p. 98). This was further supported by Usher (2012) who stated that "to feel in control, students must be able to see a clear path to achieving the goal, through means they can control rather than through luck or chance. Control is also maximized when students set goals themselves, or at least agree with and internalize goals set for them by someone else".

LoC theory also suggests that attributions students hold can have a pervasive effect on their academic achievement and, by extension, their wellbeing (Banks and Woolfson 2008). According to Schunk and Zimmerman (2006), an attribution means the perceived cause of an event or outcome. Early identification of students having negative attributions is therefore very integral to inclusiveness in the design and delivery of student support services.

\section{Theoretical Framework}

The Internality treatment used in this study is based on goal setting and achievement efforts and outcomes. This research is thus anchored on Mastery and Goal Setting theories. Mastery, according to Aneshensel, Phelan, and Bierman (2006), is one of many sociological constructs related to Personal Control. Likewise, goal setting has a positive influence on performance (Locke \& Latham, 2002) and increases goal achievement outcomes (Schunk \& Swartz, 1993). In this line of thinking, planning, striving and labouring diligently, are tantamount to the effort which should be expended in the achievement of goals as a sustainable practice. Additionally, according to Jowkar, Kojuri Kohoulat \& Hayat (2014), "in the past two decades, research findings established achievement goal theory as a powerful framework for conceptualising differences in the quality of student's engagement, persistence on a task and academic resilience".

\section{METHODOLOGY AND METHODS}

This study employed a quantitative methodology, adhered to a longitudinal, quasi-experimental (prepost, double group) research design, and used a survey as the method of data collection. New undergraduate students (334) registered for semester one, in the faculty with the highest enrolment $(1,062)$ at the university under study, were surveyed.

According to Krejcie and Morgan (1970), at a confidence level of 0.05 (95\%), a sample size of 86 for a population of 110 , is credible however, of the population of 108 students who were found to be Externals on entry to the university at Time 1, a sample of only 54 students progressed to the advanced stages of the research which involved being assigned to one Control and one Treatment Group. This assignment was based on convenience and the availability of these 54 students. Those who indicated their 
unwillingness or unavailability to receive the Treatment, were assigned to the Control Group particularly, as participation at every stage of the research was voluntary and based on informed consent.

Consequentially, the Treatment group comprised of 30 student Externals, who attended the Workshop (only 29 though, completed all aspects), which served as the channel through which the treatment (teaching of the SIMPLE Strategy - 'T') was administered. Both groups were retested at Time 2, at the end of the semester however, not all participants of the Treatment group participated as six students did not complete the survey on the second occasion.

The Hypotheses which were thus relevant and were tested are as follows:

H10: The generalized LoC score of externals exposed to the SIMPLE Strategy will NOT change at Time 2 (after treatment).

H1a: The generalized LoC score of externals exposed to the SIMPLE Strategy will change at Time 2 (after treatment).

H20: Teaching the SIMPLE Strategy had NO substantial/sizeable effect on the generalized LoC Score of the Treatment Group

H2a: Teaching the SIMPLE Strategy had a substantial/sizeable effect on the generalized LoC Score of the Treatment Group

\section{FINDINGS/RESULTS}

The External Locus of Control scores for the sample of 108 participants at Time $1\left(\mathrm{eLoC}_{1}\right)$ were nonnormal but homogeneous. The External Locus of Control (eLoC) scores at Time $2\left(\mathrm{eLoC}_{2}\right)$ as well as the eLoC difference $\left(\mathrm{eLoC}_{\mathrm{d}}\right)$ for the sample of 54 participants [Control $\left(\mathrm{n}_{1 \& 2}=25\right)$ and Treatment $\left(\mathrm{n}_{1}=29\right.$ but $\left.\mathrm{n}_{2}=24\right)$ ] were normal and homogeneous. Summary statistics and use of the T-Test were applicable. Both Independent and Paired sample statistics however, were accrued (See Tables 3 and 5 and Appendices 1 to $5)$. 
TABLE 1

TABULATED RESULTS REGARDING THE HYPOTHESES TESTED

\begin{tabular}{|c|c|c|c|}
\hline \multicolumn{2}{|c|}{ Hypothesis } & \multirow{2}{*}{$\begin{array}{l}\text { Annotation } \\
\overline{\mathrm{x}} \mathrm{eLoC}_{1}=\overline{\mathrm{x}} \mathrm{eLoC}_{2}\end{array}$} & \multirow{2}{*}{$\begin{array}{l}\text { Findings/Results } \\
\text { REJECTED: } \\
(\mathrm{p}<0.05 ; 0.022<0.05 \text { - See Table 5) }\end{array}$} \\
\hline $\mathrm{H1}_{\mathbf{0}}$ & $\begin{array}{l}\text { The Generalized LoC mean score of } \\
\text { Externals exposed to the SIMPLE } \\
\text { strategy (Treatment Group) will NOT } \\
\text { change at Time } 2 \text { (after treatment) }\end{array}$ & & \\
\hline \multirow[t]{2}{*}{$\mathbf{H 1}_{\mathbf{a}}$} & $\begin{array}{l}\text { The Generalized LoC mean score of } \\
\text { Externals exposed to the SIMPLE } \\
\text { strategy (Treatment Group) } \\
\text { change at Time } 2 \text { (after treatment) }\end{array}$ & $\overline{\mathrm{x}} \mathrm{eLoC}_{1} \neq \overline{\mathrm{x}} \mathrm{eLoC}_{2}$ & $\begin{array}{l}\text { ACCEPTED SINCE: } \\
\text { There was a decrease in the mean } \\
\text { LoC score at Time } 2 \text { for the } \\
\text { Treatment Group (See Table 2) }\end{array}$ \\
\hline & & & $\begin{array}{lll}\text { 1. } & \mathrm{H1}_{\mathbf{0}} & : \bar{x} \mathrm{eLoC}_{1}=18.29 \\
\text { 2. } & \mathrm{H} 1_{\mathrm{a}} & : \bar{x} \mathrm{eLoC}_{2}=14.33\end{array}$ \\
\hline $\mathbf{H} \mathbf{2}_{\mathbf{0}}$ & $\begin{array}{l}\text { Teaching of the SIMPLE Strategy had } \\
\text { NO substantial/sizeable effect (Design } \\
\text { Effect }-D_{\text {eff }} \text { ) on the generalized LoC } \\
\text { Score of the Treatment Group }\end{array}$ & $\begin{array}{l}\text { SIMPLE r } \not 9 \% \\
\text { (i.e. } r \not 0.30)\end{array}$ & REJECTED \\
\hline \multirow[t]{2}{*}{$\mathbf{H} \mathbf{2}_{\mathrm{a}}$} & $\begin{array}{l}\text { Teaching the SIMPLE Strategy had a } \\
\text { substantial/sizeable effect (Design } \\
\text { Effect }-D_{\text {eff }} \text { ) on the generalized LoC } \\
\text { Score of the Treatment Group }\end{array}$ & $\begin{array}{l}\text { SIMPLE } r \geq 9 \% \\
\text { (i.e. } r \geq 0.03 \text { ) }\end{array}$ & $\begin{array}{l}\text { ACCEPTED SINCE: } \\
\text { 1. } r=\sqrt{\frac{t^{2}}{t^{2}+d f}}\end{array}$ \\
\hline & & & $\begin{array}{l}\text { 2. } r=\sqrt{\frac{2.358}{5.560164+48}} \\
\text { 3. } r=0.3222=9 \% \\
\text { (Medium Effect as the effect } \\
\text { explains 9\% of the total variance - } \\
\text { Cohen, 1992;1988) }\end{array}$ \\
\hline
\end{tabular}


TABLE 2

MEAN LOC SCORES AT TIME 1 AND TIME 2 FOR THE TREATMENT GROUP

\begin{tabular}{|c|c|c|c|c|c|}
\hline $\begin{array}{l}\text { LoC SCORES } \\
\text { GROUP) }\end{array}$ & (TREATMENT & \multicolumn{2}{|l|}{ TIME 1} & TIME 2 & \multirow[b]{2}{*}{$\begin{array}{l}\text { Std. } \\
\text { Error }\end{array}$} \\
\hline & & Statistic & $\begin{array}{l}\text { Std. } \\
\text { Error }\end{array}$ & Statistic & \\
\hline Mean & & 18.29 & .472 & 14.33 & .857 \\
\hline Confidence & Lower Bound & 17.32 & & 12.56 & \\
\hline Interval for Mean & Upper Bound & 19.27 & & 16.11 & \\
\hline $5 \%$ Trimmed Mean & & 18.07 & & 14.30 & \\
\hline Median & & 17.00 & & 14.00 & \\
\hline Variance & & 5.346 & & 17.623 & \\
\hline Std. Deviation & & 2.312 & & 4.198 & \\
\hline Minimum & & 16 & & 6 & \\
\hline Maximum & & 25 & & 24 & \\
\hline Range & & 9 & & 18 & \\
\hline Interquartile Range & & 3 & & 6 & \\
\hline Skewness & & 1.269 & .472 & .041 & .472 \\
\hline Kurtosis & & 1.520 & .918 & .464 & .918 \\
\hline
\end{tabular}

Notwithstanding that there was a decrease in the mean LoC score for the treatment group at Time 2 (See Table 2), it is significant to also note that there was too, a decrease in the mean LoC score $\left(\operatorname{LoC}_{1}=18.45 ; \operatorname{LoC}_{2}=16.86\right)$ of the paired sample comprising both the Control and Treatment Groups as tabulated directly below (See Table 3 ).

TABLE 3

\section{PAIRED SAMPLE STATISTICS FOR THE GENERALIZED LOC SCORES AT TIME 1 AND} AT TIME 2 FOR BOTH THE CONTROL AND TREATMENT GROUPS

\begin{tabular}{|c|c|c|c|c|c|c|}
\hline \multicolumn{7}{|c|}{ Paired Samples Statistics } \\
\hline & & Mean & $\mathrm{N}$ & $\begin{array}{l}\text { Std. } \\
\text { Deviation }\end{array}$ & $\begin{array}{l}\text { Std. } \\
\text { Mean }\end{array}$ & Error \\
\hline \multirow{2}{*}{ Pair 1} & LoC Score1 & 18.45 & 49 & 2.227 & .318 & \\
\hline & LoC Score 2 & 16.86 & 49 & 4.713 & .673 & \\
\hline
\end{tabular}

To establish a baseline for an acceptable level of internal validity in light of the small samples used for both the Control $\left(\mathrm{n}_{1 \& 2}=25\right)$ and Treatment $\left(\mathrm{n}_{1}=29\right.$ but $\left.\mathrm{n}_{2}=24\right)$ groups, the participants were screened at the start of the semester (pre-tested) before they had a chance to fully acclimatize to the tertiary environment as new incoming students. The internality treatment was issued early into the semester to the treatment group only, and the control group was sourced and voluntarily drawn from the same population of 108 externals.

Both groups were re-tested (post-test) at the end of the semester and the control group did not as anticipated, show a reduction in its mean (18.60 at Time 1 and 19.28 at Time 2: See Table 4) external LoC score (eLoC), which is plausible for the research as the treatment was administered (teaching of the strategy) before the effects were measured at the end of semester one.

The mean LoC score of the Control group which received no treatment however, increased at Time 2 as seen in Table 4. Though credible for the research agenda, this increase can be attributable to many 
reasons including but not limited to, increased feelings of helplessness as a result of an inability to have had fully assimilated into the new environment which is more advanced than they would have encountered prior; shifting life circumstances; fluid and diverse family dynamics; and socio-economic and demographic characteristics. Additionally, students when tested at Time 2 were not in an academic mode meaning, that final examinations had concluded and they had simply slowed down in regard to their academic-related momentum. In each of these cases however, further research is necessary to test such assumptions all of which impact the intensity of their Externality orientation.

TABLE 4

MEAN LoC SCORES AT A TIME 1 AND TIME 2 FOR THE CONTROL GROUP

\begin{tabular}{|c|c|c|c|c|c|}
\hline \multirow{2}{*}{\multicolumn{2}{|c|}{$\begin{array}{l}\text { LoC SCORES } \\
\text { (CONTROL GROUP) }\end{array}$}} & \multicolumn{2}{|l|}{ TIME 1} & \multicolumn{2}{|l|}{ TIME 2} \\
\hline & & Statistic & $\begin{array}{l}\text { Std. } \\
\text { Error }\end{array}$ & Statistic & $\begin{array}{l}\text { Std. } \\
\text { Error }\end{array}$ \\
\hline Mean & & 18.60 & .436 & 19.28 & .776 \\
\hline $95 \%$ & Lower & 17.70 & & 17.68 & \\
\hline Confidence & Bound & & & & \\
\hline Interval for & Upper & 19.50 & & 20.88 & \\
\hline Mean & Bound & & & & \\
\hline \multicolumn{2}{|c|}{$5 \%$ Trimmed Mean } & 18.50 & & 19.19 & \\
\hline \multicolumn{2}{|l|}{ Median } & 18.00 & & 20.00 & \\
\hline \multicolumn{2}{|l|}{ Variance } & 4.750 & & 15.043 & \\
\hline \multicolumn{2}{|c|}{ Std. Deviation } & 2.179 & & 3.879 & \\
\hline \multicolumn{2}{|l|}{ Minimum } & 16 & & 13 & \\
\hline \multicolumn{2}{|l|}{ Maximum } & 23 & & 28 & \\
\hline \multicolumn{2}{|l|}{ Range } & 7 & & 15 & \\
\hline \multicolumn{2}{|c|}{ Interquartile Range } & 3 & & 7 & \\
\hline \multicolumn{2}{|l|}{ Skewness } & .850 & .464 & .128 & .464 \\
\hline \multicolumn{2}{|l|}{ Kurtosis } & -.068 & .902 & -.419 & .902 \\
\hline
\end{tabular}

\section{Reporting on Hypothesis 1}

The generalised LoC mean score of Externals who received Treatment reduced at Time 2, The mean LoC score for the sample which received the SIMPLE Strategy Instruction subsequent to being tested at the end of the semester, was lower than the mean LoC score of this same sample prior to treatment at the beginning of the semester and also lower than the mean LoC score of the Control group which received no training and for which the scores significantly increased on re-test at Time 2 .

\section{Reporting on Hypothesis 2}

Design Effect $\left(\mathrm{D}_{\text {eff }}\right) /$ Estimate of overall Variance- Magnitude/Significance of the Effect of the SIMPLE strategy on the Generalized LoC Score of the Treatment Group was found to be medium $(\mathbf{r}=\mathbf{0 . 0 3} ; \mathbf{9 \%})$. Notwithstanding the fact that the likelihood of the level of significance regarding the two means (Time 1 and Time 2 for the LoC scores) was significant $(p<0.05 ; 0.022<0.05$ - See Table 5) in calculating the Design Effect ( $D_{\text {eff }}$ - estimate of total variance) to determine the extent to which the teaching and use of the SIMPLE Strategy contributed to the change which was observed for the treatment group at Time 2, it was found that only $9 \%$ of the variance could be attributed to the SIMPLE Strategy Instruction $(r=0.32)$.

According to Cohen's $(1992 ; 1988)$, reliable suggestions regarding what constitutes a large or small effect, and which are accepted widely, when $r=0.3$, it corresponds to a medium effect and accounts for 
$9 \%$ of the total variance; when $r=0.1$, it corresponds to a small effect and accounts for $1 \%$ of the total variance and when $r=0.5$, it corresponds to a large effect and accounts for $25 \%$ of the total variance.

\section{TABLE 5 \\ PAIRED SAMPLE T-TEST THE GENERALIZED LoC SCORES AT TIME 1 AND TIME 2 FOR BOTH THE CONTROL AND TREATMENT GROUPS}

\begin{tabular}{|c|c|c|c|c|c|c|c|c|c|c|}
\hline \multicolumn{11}{|c|}{ Paired Samples Test } \\
\hline & & & \multicolumn{5}{|c|}{ Paired Differences } & \multirow[b]{5}{*}{$\mathrm{t}$} & \multirow[b]{5}{*}{ df } & \multirow{5}{*}{$\begin{array}{l}\text { Sig. } \\
(2- \\
\text { tailed })\end{array}$} \\
\hline & & & \multirow[b]{4}{*}{ Mean } & \multirow{4}{*}{$\begin{array}{l}\text { Std. } \\
\text { Deviation }\end{array}$} & \multirow{4}{*}{$\begin{array}{l}\text { Std. } \\
\text { Error } \\
\text { Mean }\end{array}$} & \multirow{3}{*}{\multicolumn{2}{|c|}{$\begin{array}{l}95 \% \\
\text { Confidence } \\
\text { Interval of the } \\
\text { Difference }\end{array}$}} & & & \\
\hline & & & & & & & & & & \\
\hline & & & & & & & & & & \\
\hline & & & & & & Lower & Upper & & & \\
\hline $\begin{array}{l}\text { Pair } \\
1\end{array}$ & $\begin{array}{l}\text { LoC } \\
\text { Score1 } \\
\text { LoC } \\
\text { Score2 }\end{array}$ & - & 1.592 & 4.725 & .675 & .235 & 2.949 & 2.358 & 48 & .022 \\
\hline
\end{tabular}

\section{DISCUSSION}

According to Hill (2011b), the Personal Achievement Strategy (PAS) was designed and intended to teach Internality which is characteristic of, and synonymous with, resilience, other desirable behaviours, and overall life outcomes. This internality treatment was thus developed and delivered in a workshop format (ellipsis conceptualised and operationalised by the researcher) termed the SIMPLE Strategy (appendix A) and it was issued early into the semester to the treatment group (pre-tested) before they had a chance to fully acclimatize to the tertiary environment as new incoming students.

The workshop was designed to ensure that stages $\underline{\mathbf{S}}$ to $\underline{\mathbf{P}}$ ( $\underline{\mathbf{S}}$ elf Study, Generating Goal $\underline{\mathbf{I}}$ deas;

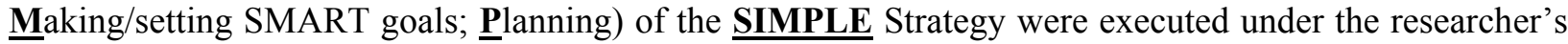
supervision during the workshop, in an effort to teach the strategy and to guide and ensure that the strategy was well taught and understood by all attendees using the same standard. As explained to the treatment group stage $\mathbf{L}$ (Labouring) was to be executed during the semester while stage $\underline{\mathbf{E}}$ (Evaluation) was to be executed at the end of the semester. The ellipsis SIMPLE was thus established by the author of this current study to ensure that the use, and the reporting on the efficiency of this use, of the strategy, were well aligned and consistent for all attendees who received training.

Two members of the treatment group who initially both scored as externals at Time 1 at the beginning of the semester, scored as internals (Score 6) at Time 2, having a LoC difference of 11 and 12 respectively. Although the SIMPLE Strategy accounts for only $9 \%$ of this effect, on the Treatment group, in comparison to the Control group however, this was indeed a desirable outcome as the main aim of this research was to teach internality and to re-test subsequent to treatment. While a good majority of the treatment group moved from being externals (score range of 16-40), to intermediates (score range of 7 15 ), only these two shifted directly to internality (score range of 0-6).

Another aim of this research was to advance a case regarding the importance of proactive, rather than reactive, inclusive student support service initiatives in a tertiary setting. In this line of thinking, the PAS should indeed be taught to students found to be Externals via its researcher developed workshop format termed the SIMPLE Strategy. Although the findings are only applicable to a specific group totalling 54 participants ( 25 control group members ' $C$ ' and 29 treatment group members ' $T$ '), any doubt should have been remedied in the minds of readers of this research, to sufficiently generate support for the explicit and important role that the SIMPLE workshop strategy, can serve, to develop Internality, and so too, the 
wellbeing and academic goal-setting competencies of tertiary level students which is understandably more desirable.

Moreover, this current research which used a Caribbean sample as the point of contrast, was conducted almost fourteen (14) years (in 2016), since Twenge, Zhang and Im's (2004) research. Tweng, Zhang and Im's research, as mentioned earlier, was conducted over thirty years after Rotter's 1971 study. It confirmed Rotter's (1971) prediction that the orientation of individuals continues to be majorly External, and should efforts not be extended with urgency, to reverse this severe trend, the leaders of tomorrow could manifest maladjusted attributions in keeping with externality, and the overall impact could be far-reaching and possibly undesirable.

Institutions of learning thus need to fulfil their manifest functions and social responsibilities with the highest regard for inclusion, egalitarianism, proactivity and value, in contributing to the development of individuals, who are fit to serve in leadership and other sustainable and beneficial capacities, toward nation building and sustenance.

There is though, some empirical research yet to be done concerning these matters at HEIs, specifically in a Caribbean setting. The data presented herein by themselves cannot offer a full length and breadth review of the information needed to determine the required social and conditional changes at the university herein studied, or the society by extension. It cannot be expected either, to facilitate the complete comprehension of the role Hill's (2011b) Personal Achievement Strategy (PAS) can play in the academic success outcomes of tertiary students as a universal model. This paper has laid the foundation and further data from this same study will be gleaned and used in subsequent research to attempt to further answer questions emanating either directly or indirectly, from the areas of analysis.

\section{RECOMMENDATIONS}

It is thus recommended that the teaching of the PAS should be delivered via the workshop tertiary format (SIMPLE strategy) and offered as a co-curricular course at the university under study, especially considering that various research findings including those of this current research, give credence to the viability of the strategy. Workshop enrolment can be optional for those new students screened and found to be Internals or Intermediates and mandatory for Externals. Internals can volunteer to serve as a means to earn co-curricular credits through mentoring and/or internality coaching services which would be extended to externals and others as needed as part of the intervention efforts.

\section{CONCLUSION}

Similar to research conducted in the international setting of Philadelphia many years ago in 1972, this research which was conducted in 2016, had similar results in that, the six step Internality instruction developed by Hill and his colleagues and which was altered by the researcher of this current study was effective in transforming Internality to Externality. In this study the effect of the SIMPLE strategy instruction was found to be medium at $9 \%$. Future research is needed using different LoC scales for Caribbean samples to further solidify generalisations regarding internality instruction.

There needs to also be a revolutionary paradigm shift so that inclusion is no longer examined or considered through myopic lenses which only advocate for increased access; education for all; and improvement in classroom instruction and engagement through blended technologies etc. It should also focus on an equality of condition for achievers and underachievers; on closing the gap between students who are disposed to richer cultural, emotional, physical, and economic capital and those who are not do not, and thus are afforded much fewer opportunities. 


\section{REFERENCES}

Abe, I. I., Ilogu, G. C., \& Madueke, I. L. (2014). Effects of Goal-Setting Skills on Students' Academic Performance in English Language in Enugu Nigeria. Journal of New Approaches in Educational Research 3(2), 93-99.

Aneshensel, C. S., Phelan, Jo, C., \& Bierman, A. eds. (2006). Handbook of the Sociology of Mental Health. 2nd ed. New York, NY: Springer.

Banks, M., \& Woolfson, L. (2008). Why Do Students Think They Fail? The Relationship between Attributions and Academic Self-Perceptions. British Journal of Special Education, 35(1), 49-56.

Cohen, J. (1988). Statistical power analysis for the behavioral sciences (2nd ed.). Hillsdale, NJ: Lawrence Earlbaum Associates

Cohen, J. (1992). A power primer. Psychological Bulletin, 112(1), 155-159.

Effect Sizes-Discovering Statistics (n.d.). Retrieved February 3, 2017, from http://www.bing.com/cr?http://www.bing.com/cr?IG=1B73A1DB6EE240C4A48564EB19236A BA\&CID=0A40618CF7C560B8323F6A5EF66A61E8\&rd=1\&h=HJ10QFlj0Jdn2hEdYt4WP66YgQQXrwuUWBPlxxyRJE\&v=1\&r=http\%3a\%2f\%2fwww.discoveringstatistics.com $\% 2 \mathrm{fdocs} \%$ 2 feffectsizes.pdf\&p=DevEx,5068.1 - http://www.discoveringstatistics.com/docs/effectsizes.pdf

Florian, L., Rouse, M., \& Black-Hawkins, K. (2016). Achievement and inclusion in schools. Routledge.

Golding, J., Iles-Caven, Y., Gregory, S., \& Nowicki, S. (2017). The antecedents of women's external locus of control: associations with characteristics of her parents and of early childhood. Heliyon 3:e00236. doi:10.1016/j.heliyon.2017.e00236

Hadsel, L. (2010). Achievement goals, locus of control, and academic success in economics. American Economic Review, 100(2), 272-276

Halpert, R., \& Russ, H., (2011). The Locus of Control Construct's Various Means of Measurement: A Researcher's Guide to Some of the More Commonly Used Locus of Control Scales. Beach Haven, NJ: Will to Power Press.

Hill, R. (2011a). The Exciting and Compelling Value of Being "INTERNAL": A Compilation of Research Studies Supporting the Value of Exhibiting Internal Locus of Control. Beach Haven, NJ: Will to Power Press.

Hill, R. (2011b). Teach Internal Locus of Control: A Positive Psychology App. Beach Haven, NJ: Will to Power Press.

Jowkar, B., Kojuri, j., Kohoulat, N., \& Hayat, A. A. (2014). Academic resilience in education: the role of achievement goal orientations. Journal of advances in medical education \& professionalism, 2(1), 33.

Kader, A. A. (2014). Locus of control, student motivation, and achievement in principles of microeconomics. American International Journal of Contemporary Research, 4(9), 1-11.

Krejcie, R. V., \& Morgan, D.M. (1970). Determining Sample Size for Research Activities. Educational and Psychological Measurement, 30(3), 607-10.

Landrum, E.R. (2010). Intent to Apply to Graduate School: Perceptions of Senior Year Psychology Majors.North American Journal of Psychology, 12(2), 243-54.

Lefcourt, H., M. (2014). Locus of Control: Current Trends in Theory and Research. 2nd ed. New York, NY: Psychology Press.

Locke, E. A., \& Latham, G. P. (1990). A theory of goal setting and task performance. Englewood Cliffs, NJ: Prentice-Hall.

Nowicki, S., Jr, \& Duke, M.P. (1974). A Locus of Control Scale for Non-college as well as College Adults. Journal of Personality Assessment, 38(2), 136-37.

Olani, A. (2009). Predicting First Year University Students' Academic Success. Electronic Journal of Research in Educational Psychology, 7(3), 1053-72.

Pannells, T.C., \& Claxton, A. F. (2008). Happiness, Creative Ideation, and Locus of Control. Creativity Research Journal, 20(1), 67-71. 
Perry, E., \& Francis, B. (2010). The Social Class Gap for Educational Achievement: A Review of the Literature. London: RSA Projectsas cited in Florian, L., Rouse, M., \& Black-Hawkins, K. (2016). Achievement and inclusion in schools. Routledge.

Rotter, J. B. (1990). Internal versus External Control of Reinforcement: A Case History of a Variable. American Psychologist, 45(4), 489-93.

Rotter, J. B. (1971). Who Rules You? External Control and Internal Control. Psychology Today, 5(1), $37-$ $42,58-59$.

Rotter, J. B. (1966). Generalized Expectancies for Internal versus External Control of Reinforcement. Psychological Monographs, 609. Washington, DC: American Psychological Association.

Skinner, E. A. (1996). A Guide to Constructs of Control. Journal of Personality and Social Psychology, 71(3), 549-70.

Stipek, D. J., \& Weisz, J. R. (1981). Perceived Personal Control and Academic Achievement. Review of Educational Research, 51(1), 101-37.

Schunk, D. H., \& Swartz, C. W. (1993). Goals and progress feedback: Effects on self-efficacy and writing achievement. Contemporary Educational Psychology, 18, 337-354. doi: 10.1006/ceps.1993.1024

Schunk, D. H., \& Zimmerman, B. J. (2006). Competence and Control Beliefs: Distinguishing the Means and Ends. In Handbook of Educational Psychology, edited by Patricia A. Alexander, and Philip H. Winne. Mahwah, NJ: Lawrence Erlbaum Associates, Inc.

Twenge, J.M., Zhang, L., \& Im, C. (2004). It's Beyond My Control: A Cross-Temporal Meta-Analysis of Increasing Externality in Locus of Control, 1960-2002. Personality and Social Psychology Review, 8(3), 308-19.

UNESCO (2005). Guidelines for Inclusion: Ensuring Access to Education for All. Paris: UNESCO. Usher, A., \& Kober, N. (2012). Can Goals Motivate Students? Center on Education Policy. 


\section{APPENDICES}

APPENDIX 1

The SIMPLE Strategy Cyclical Process Model: Workshop Delivery Format for tertiary aged students as Adapted from the PAS/ACT Strategy Format

Source: Hill (2011b)

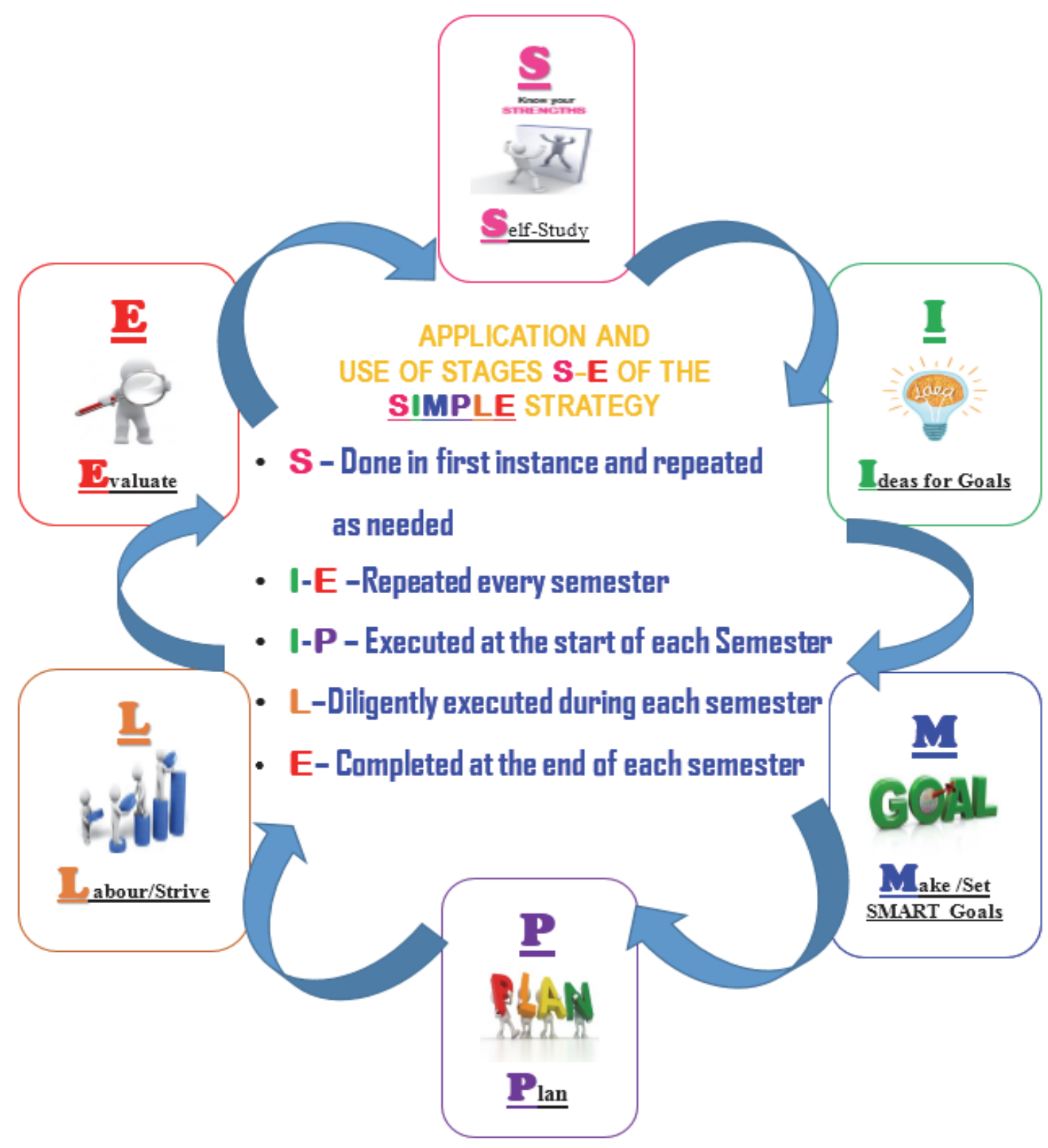


APPENDIX 2

TREATMENT GROUP PROCESSING SUMMARY

\begin{tabular}{|c|c|c|c|c|c|c|c|}
\hline \multirow[b]{2}{*}{ VARIABLES } & \multirow[b]{2}{*}{ Gender } & \multicolumn{2}{|c|}{ Valid } & \multicolumn{2}{|l|}{ Mean } & \multicolumn{2}{|l|}{ Total } \\
\hline & & $\mathbf{N}$ & $\%$ & Normal & $\begin{array}{l}5 \% \\
\text { Trimmed }\end{array}$ & Range & $\begin{array}{l}\text { Media } \\
\text { n }\end{array}$ \\
\hline \multirow[t]{2}{*}{$\overline{A G E}$} & Female & 23 & 100.0 & 18.78 & 18.71 & 3 & 19 \\
\hline & Male & 6 & 100.0 & 21.67 & 20.96 & 20 & 18.50 \\
\hline TOTAL & & 29 & & & & & \\
\hline \multirow[t]{3}{*}{ Ethnicity } & African & 6 & 100.0 & & & & \\
\hline & Indian & 10 & 66.7 & & & & \\
\hline & Mixed & 8 & 100.0 & & & & \\
\hline TOTAL & & 24 & & & & & \\
\hline \multirow[t]{2}{*}{ LoC Score 1 (T1) } & Female & 23 & 100.0 & 18.87 & 18.81 & 7 & 19 \\
\hline & Male & 6 & 100.0 & 18 & 17.72 & 9 & 16.50 \\
\hline TOTAL & & 29 & & & & & \\
\hline \multirow[t]{2}{*}{ LoC Score 2 (T2) } & Female & 19 & 100.0 & 14.53 & 14.47 & 18 & 15 \\
\hline & Male & 5 & 100.0 & 13.60 & 13.50 & 9 & 13 \\
\hline TOTAL & & 24 & & & & & \\
\hline \multirow[t]{2}{*}{ Missing Cases } & 4 Females & 5 & 17.4 & & & & \\
\hline & 1 Male & & 16.7 & & & & \\
\hline
\end{tabular}

APPENDIX 3

ETHNICITY CROSS TABULATION SUMMARY FOR EXTERNAL LOC ORIENTATION AT TIME 1 OF THE TREATMENT GROUP COMPRISING 29 PARTICIPANTS

\begin{tabular}{llllll}
\hline & \multicolumn{3}{c}{ Ethnicity } & & \\
\cline { 3 - 6 } & African & Indian & Mixed & Total \\
\hline External -Focus Time 1 & External & 6 & 15 & 8 & 29 \\
\hline Total & & 6 & 15 & 8 & 29 \\
\hline
\end{tabular}

APPENDIX 4

GENDER CROSS TABULATION SUMMARY FOR EXTERNAL LOC ORIENTATION AT TIME 1 OF THE TREATMENT GROUP COMPRISING 29 PARTICIPANTS

\begin{tabular}{lllll}
\hline & & Gender & & \\
\cline { 3 - 4 } & & Female & Male & Total \\
\hline \multirow{3}{*}{ External- Focus Time 1 } & Internal & 2 & 0 & 2 \\
& Intermediate & 10 & 4 & 14 \\
& External & 11 & 2 & 13 \\
\hline Total & & 23 & 6 & 29 \\
\hline
\end{tabular}




\section{APPENDIX 5 \\ CONTROL GROUP PROCESSING SUMMARY}

\begin{tabular}{lllllllll}
\hline \multirow{2}{*}{ VARIABLES } & Gender & $\mathrm{N}$ & $\%$ & Normal & $\begin{array}{l}5 \% \\
\text { Trimmed }\end{array}$ & $\begin{array}{l}\text { Rang } \\
\mathrm{e}\end{array}$ & $\begin{array}{l}\text { Media } \\
\mathrm{n}\end{array}$ \\
\hline AGE & $\begin{array}{l}\text { Female } \\
\text { Male }\end{array}$ & $\begin{array}{l}21 \\
4\end{array}$ & 100.0 & 18.86 & 18.79 & 3 & 19.0 \\
TOTAL & & 25 & & & & 2 & 18.50 \\
& & & & & & & \\
ETHNICITY & African & 5 & 100.0 & & & & \\
& & Indian & 14 & 100.0 & & & & \\
TOTAL & & Mixed & 6 & 100.0 & & & & \\
& & 25 & & & & & \\
LoC Score & 1 & Female & 21 & 100.0 & 18.62 & 18.52 & 7 & 18.00 \\
(T1) & Male & 4 & 100.0 & 18.50 & 18.39 & 7 & 17.50 \\
LoC Score & 2 & Female & 21 & 100.0 & 20.10 & 20.00 & 14 & 20.00 \\
(T2) & & Male & 4 & 100.0 & 15.00 & 14.89 & 6 & 14.00 \\
\hline
\end{tabular}

APPENDIX 6

CONTROL AND TREATMENT GROUP SUMMARY DATA

\begin{tabular}{llllll}
\hline & & Frequency & Percent & Valid Percent & $\begin{array}{l}\text { Cumulative } \\
\text { Percent }\end{array}$ \\
\hline Valid & Control & 25 & 7.5 & 46.3 & 46.3 \\
& Treatment & 29 & 8.7 & 53.7 & 100.0 \\
& Total & 54 & 16.2 & 100.0 & \\
\hline Missing & 99 & 280 & 83.8 & & \\
\hline Total & & 334 & 100.0 & & \\
\hline
\end{tabular}

